\title{
Serviks Kanseri İçin İki Farklı Brakiterapi Tedavi \\ Planlama Tekniğinin Dozimetrik Karşılaștırması
}

\section{Dosimetric Comparison of Two Different Brachytherapy Treatment Planning Techniques for Cervical Cancer}

Osman Vefa GÜL, Gökçen İNAN, Hamit BAŞARAN

Selçuk Üniversitesi Tıp Fakültesi, Radyasyon Onkolojisi Anabilim Dalı, Konya, Türkiye

Yazışma Adresi

Correspondence Address

\section{Osman Vefa GÜL}

Selçuk Üniversitesi Tıp Fakültesi,

Radyasyon Onkolojisi Anabilim Dalı,

Konya, Türkiye

vefagul@selcuk.edu.tr

Geliş tarihi / Received : Kasım 05, 2020 Kabul tarihi / Accepted : Aralık 30, 2020 Elektronik yayın tarihi : Ocak 01, 2022 Online published

Bu makalede yapılacak atıf: Cite this article as:

Gül O.V, İnan G, Başaran H. Serviks Kanseri İçin İki Farklı Brakiterapi Tedavi

Planlama Tekniğinin Dozimetrik

Karşılaştırması.

Akd Tip D 2022; 8(1):48-54.

Osman Vefa Gül

ORCID ID: 0000-0002-6773-3132

Gökçen İnan

ORCID ID: 0000-0003-2995-0256

Hamit Başaran

ORCID ID: 0000-0002-2122-8720

\section{ÖZ}

Amaç:

Bu çalışmanın amacı, servikal kanserin brakiterapisinde manuel olarak optimize edilmiş (MO) planlama yaklaşımı ile inverse optimize edilmiş (IO) planlama yöntemleri arasındaki dozimetrik farkl1lıkları değerlendirmektir.

\section{Gereç ve Yöntemler:}

Bu çalışmaya on beş hasta dahil edildi. Yüksek riskli klinik hedef hacim (CTVHR) ve orta riskli hedef hacim (CTVIR) CTV'ler olarak tanımland, ayrıca riskli organlar olarak (OAR) rektum, mesane, ince bağırsak, sigmoid ve üretra tanımlandı. Her hasta için iki farklı tedavi planları oluşturuldu. Bütün hastalara 50.4 Gy external ışın radyoterapisi (EBRT) uygulandıktan sonra, 4 fraksiyonda 28 Gy yüksek doz oranı (HDR) tümör merkezine verildi. Bu tedavi planlarından alınan dozimetrik sonuçlar, CTV'ler, OAR'lar, uygunluk indeksi (CI) ve toplam tedavi süresi gibi dozimetrik parametreler karşılaştırıldı.

\section{Bulgular:}

CTVHR' in D90, CTVIR' in D50 için anlamlı fark bulunamamıștır fakat CTVHR' in D98 değeri için $(p<0.000)$, CTVIR' in D90 için $(p<0.000)$ ve D98 için $(p<0.000)$, CI $(p<0.000)$, toplam dwell time $(\mathrm{p}<0.002)$. OAR'ler açısından, IO MO'dan önemli ölçüde daha iyi olduğu bulundu. (rektumun D2cm3 için $\mathrm{p}<0.043$, mesanenin $\mathrm{D} 2 \mathrm{~cm} 3, \mathrm{D} 0.1 \mathrm{~cm} 3$ ve V5Gy için $\mathrm{p}<0.000$, ince bağırsağın V5Gy için $p<0.041$, sigmoidin V5Gy için $p<0.041$, üratranın D2cm3, D0.1 cm3 ve V5Gy için $\mathrm{p}<0.000)$.

\section{Sonuç:}

OAR'lar ve hedef hacim göz önüne alındığında, IO serviks kanserinin yüksek doz oranlı brakiterapi için en uygun teknik olarak görülmektedir.

Anahtar Sözcülkler: Brakiterapi, Serviks kanseri, İnverse optimizasyon, Manuel optimizasyon

\section{ABSTRACT}

Objective:

The purpose of this study was to evaluate the dosimetric differences between inverse optimized (IO) planning methods with the manual optimized (MO) planning approach for brachytherapy of cervical cancer. 


\section{Methods:}

Fifteen patients were included in this study. High-risk clinical target volume (CTVHR) and intermediate-risk CTV (CTVIR) were defined as CTVs, and rectum, bladder, smallbowel, sigmoid and urethra, were defined as organs at risk (OARs). Two different treatment plans were created for each patient: MO and IO. After all patients received 50.4 Gy external beam radiotherapy (EBRT), 28 Gy high-dose-rate (HDR) in 4 fractions was delivered to central disease. Dosimetric outcomes from these treatment plans were compared with dosimetric parameters, such as CTVs, OARs, conformity index (CI) and total dwell time.

\section{Results:}

There were no significant differences in D90 values of CTVHR and D50 values of CTVIR, however significant differences were found D98 values of CTVHR $(p<0.000)$, and D90 values of CTVIR $(\mathrm{p}<0.000)$, and D98 values of CTVIR $(p<0.000)$, CI $(p<0.000)$, total dwell time $(p<0.002)$. In terms of OARs, IO was found to be significantly better than MO ( $p<0.043$ for D2cm 3 of rectum, $p<0.000$ for D $2 \mathrm{~cm} 3$ ,D0.1 cm 3 and V5Gy of bladder, $\mathrm{p}<0.041$ for V5Gy of small bowels, $\mathrm{p}<0.000$ for V5Gy of sigmoid, $\mathrm{p}<0.000$ for D2cm3, D0.1 cm3 and V5Gy of urethra).

\section{Conclusion:}

Considering the OARs and target volume, IO appears to be the most appropriate technique for high dose rate brachytherapy of cervical cancer.

Key Words: Brachytherapy, Cervix cancer, Inverse optimization, Manual optimization

\section{GİRIŞ}

Brakiterapi (BRT); radyoaktif kaynakların kanserli dokunun içine ya da yakınına yerleştirilmesiyle gerçekleştirilen bir tedavi biçimidir. Brakiterapi yunancada kısa anlamına gelmektedir. BRT jinekolojik kanserlerin içinde özellikle lokal ileri hastalıkların tedavisinde önde gelen bir tedavi yöntemi olarak kullanılmaktadır(1,2). 1896 yılında Becquerel uranyum kristalleri üzerinde deney yaparken radyoaktiviteyi bulmuş ve bunu 1898 yılında Marie ve Pierre Curie'nin radyumu keşfi takip etmiştir. Kanserli yapılarda ilk başarılı radyum brakiterapisi 1903 y1lında St.Petersburg'da yüzeyel bazal cell karsinomlu iki hastanın tedavisi ile yapılmıştır. Aynı yıl serviks kanserlerinde radyum uygulamasının etkisi rapor edilmiş ve jinekolojide brakiterapi uygulamaları başlamıştır (3). BRT özellikle jinekolojik kanserler için hayati bir önem taşımaktadır. Günümüzde eksternal tedavi ve kemoterapi ile birlikte standart tedavi metodu olarak uygulanır (4). Lokal tümör tedavisinde BRT' nin özellikle kritik organları koruma açısından büyük bir üstünlüğü vardır. BRT, kullanımı açısından hastalığın evrelemesine göre değişiklik göstermektedir. Evreye göre, erken evrelerde tek başına, ileri evrelerde ise kemoradyoterapi tercih edilebilmektedir (5).

Brakiterapide kullanılan kaynaklar farklı doz hızlarına sahiptir. Kaynak hızlarına göre brakiterapi International Commission on Radiation Units and Measurements (ICRU) 38 no'lu raporuna göre dört sınıfa ayrılabilir. Düşük doz hızlı (LDR); doz hızı 0,4-2 Gy/saat aralığındadır, kullanılan kaynak aktiviteleri $1-5 \mathrm{mCi} / \mathrm{cm}$ arasında değişir ve tedavi günler sürebilir. Orta doz hızlı (MDR); doz hızı 2-12 Gy/saat aralığındadır, tedavisi ortalama 6-8 saat aralığında sürmektedir bu yüzden çok kullanılan bir yöntem değildir. Yüksek doz hızlı (HDR); doz hızı 12 Gy/saat'den daha büyük doz hızına sahiptir, tedavi dakikalar mertebesindedir ve uygulama sekline göre 4-6 fraksiyon uygulanmaktadır, HDR cihazlarda kullanılan kaynak aktivitesi $10 \mathrm{Ci}$ civarındadır. Puls doz hızlı (PDR);doz hızı saatte 1-3 Gy/saat'dir, 0.5-1 Ci aktiviteli Ir192 kaynakları kullanılarak belirli aralıklar ile 5-10 dk. süren HDR pulsları şeklinde uygulanır, HDR cihazı kullanılarak LDR tedavilerinin radyobiyolojik etkisi elde edilir (6). HDR brakiterapide doz hızı etkisi kritik bir faktördür. Doz hızındaki bir artış, toplam dozda bir azalmayı gerektirir ki, çevre normal dokularda aşırı doza neden olmasin (7).

İridyum-192, kaynağının yaydığı gamma 1şının spektrumun ortalama enerjisi $0.38 \mathrm{MeV}$ ' dir. Günde yaklaşık \%1 kadarlık radyoaktif bozunuma uğramaktadır. Ir-192 radyoaktif kaynağına HVL' (yarı değer kalınlığı) si doku için $6 \mathrm{~cm}$; kurşun için 2,5 mm' lik kurşun yeterli gelmektedir. Ir-192 \%95 oranında beta bozunumu yaparak Pt-192' ye dönüşmektedir. Kaynağın aktivitesi $10 \mathrm{Ci}$ (Curie)'dir. Gamma ışını yayarak stabil hale gelir (8).

Brakiterapi tedavilerinde, hedef hacmin yakınındaki vücut boşluklarına radyoaktif kaynakların yerleştirilmesiyle yapılan intrakaviter tedavi ve radyoaktif kaynakların hedef hacmin içine yerleştirilerek yapılan intertisyel tedavi olmak üzere başlıca iki tedavi yöntemi vardır. Diğer tedavi yöntemleri ise radyoaktif kaynakların tedavi edilecek dokunun üzerine yerleştirilmesine yüzeyel ( mold ) uygulama, bir lümen içine yerleştirilmesine intraluminal uygulama, ameliyat sırasında hedef hacmin içine yerleştirilmesine intraoperatif uygulama, tek bir kaynağın arterlerin içine yerleştirilmesine de intravasküler uygulama olarak adlandırılır. İntertisyel uygulamalar geçici veya kalıcı olabilirken intrakaviter brakiterapi tedavileri her zaman geçici ve kısa sürelidir $(9,10)$. Eskiden brakiterapi'de kaynaklar, aplikatör içine ve hedef hacim içine elle yerleştirilip geri alındığı için tıbbi ve teknik personel radyasyona maruz kalmaktaydı. Radyasyona maruz kalma riskini en aza indirgemek için uzaktan sonradan yüklemeli ( remote afterloading ) sistemler geliştirilmiştir $(11,12)$. Serviks, uterusun alt kısmına verilen addır. Serviks üreme sistemimizin bir parçası olup; uterus ve vajinayı birleştiren iki kısımdan oluşmaktadır. Günümüzde serviks kanseri kadınlar için önemli bir sağlık sorununu teşkil etmektedir. Primer tümörün boyutunu ve yayılımını değerlendirmek hastalığın yönetim planını belirlemekte en önemli basamaktır. Bu değerlendirme klinik The International Federation of Gynecology and Obstetricss (FIGO) evrelemesi, cerrahi evreleme (laparoskopik ve laparotomik) ve görüntüleme yöntemleri ile MRG, pozitron emsiyon tomografi (PET) ve bilgisayarlı tomografi (BT) ile yapılabilir. Erken evre serviks kanserinde cerrahi ve EBRT eşdeğer sağ kalım oranları elde edilmekte; ileri evre serviks kanserlerinde lokal kontrol EBRT ile sağlanmaktadır. Kanserin evresi tedavi uygula- 
masında belirleyicidir, erken evrelerde BRT tek başına uygulanır (13).

Brakiterapide farklı tedavi optimizasyonları bulunmaktadır. HDR BRT' de doz, planlama aşamasında kaynak duruş yerlerindeki ışınlama sürelerinin değiştirilmesiyle kontrol edilir. BRT planlamalarında kaynak duruş sürelerinin veya ağırlıklarının manuel değiştirme yoluyla optimizasyon işlemine manuel optimizasyon (MO) denir. Bu metotta, duruş sürelerinin sürekli değiştirilmesiyle, kriterleri sağlayan doz dağılımı deneme-yanılma yöntemiyle elde edilmeye çalışılmaktadır. $\mathrm{Bu}$ süreç planlayıcının tecrübesine bağlı olarak değişir (14). BRT planlamasında çok sayıda kaynak pozisyonu ve hedeflenen çok sayıda kriterin olduğu uygulamalarda optimum planı oluşturmak için kullanılan optimizasyon işlemine inverse optimizasyon (IO) denir. IO, BRT planlamalarında daha hızlı çözümler sunarak, istenene en yakın doz dağılımları elde edilmesini sağlayabilir(15-17).

Bu çalışmada amacımız retrospektif olarak elde edilen FIGO evrelemesi IIB ve IIIB olan 15 serviks kanseri tanılı her bir hasta için, CTVHR'e 4 fraksiyonda toplamda 28 Gy alacak şekilde yapılan MO ve IO planlarının ortalamalarını dozimetrik olarak karşılaştırmaktır.

\section{GEREÇ ve YÖNTEM}

Bu çalışmada Ocak 2020-Eylül 2020 tarihleri arasında Selçuk Üniversitesi Tıp Fakültesi Hastanesi Radyasyon Onkolojisi Anabilim Dalı'nda brakiterapi tedavisi gören 15 serviks kanseri hasta retrospektrif olarak yeniden değerlendirildi. Selçuk Üniversitesi Tıp Fakültesi Yerel Etik Kurulu'ndan 30.09.2020 tarih 2020/424 say1lı izin alındı ve makalede Araştırma ve Yayın Etiğine uyuldu. Selçuk Üniversitesi Tıp Fakültesi Radyasyon Onkolojisi Anabilim Dalı' nda eşzamanlı kemoradyoterapi (KRT) ile tedavi edilen FIGO evre II ve III serviks kanseri olan 15 hasta çalışmaya dahil edildi. Tüm hastaların FIGO evreleme dağılımı Tablo I' de sunulmuştur.

\begin{tabular}{|l|l|l|l|l|l|l|}
\hline Hasta & Yaş & Tedavi & $\begin{array}{l}\text { FIGO } \\
\text { Evre }\end{array}$ & Histoloji & $\begin{array}{l}\text { Dose/Fr } \\
\text { Gy / Gün }\end{array}$ & $\begin{array}{l}\text { BRT } \\
\text { (cGy) }\end{array}$ \\
\hline 1 & 76 & EBRT+BRT & IIB & SCC & $504 / 28$ & 4 X700 \\
\hline 2 & 82 & EBRT+BRT & IIIB & SCC & $504 / 28$ & $4 X 700$ \\
\hline 3 & 58 & EBRT+BRT & IIIB & SCC & $504 / 28$ & $4 X 700$ \\
\hline 4 & 60 & EBRT+BRT & IIIB & SCC & $504 / 28$ & $4 X 700$ \\
\hline 5 & 42 & EBRT+BRT & IIB & SCC & $504 / 28$ & $4 X 700$ \\
\hline 6 & 49 & EBRT+BRT & IIB & SCC & $504 / 28$ & $4 X 700$ \\
\hline 7 & 56 & EBRT+BRT & IIIB & SCC & $504 / 28$ & $4 X 700$ \\
\hline 8 & 58 & EBRT+BRT & IIIB & SCC & $504 / 28$ & $4 X 700$ \\
\hline 9 & 65 & EBRT+BRT & IIIA & SCC & $504 / 28$ & $4 X 700$ \\
\hline 10 & 45 & EBRT+BRT & IIB & SCC & $504 / 28$ & $4 X 700$ \\
\hline 11 & 55 & EBRT+BRT & IIIB & SCC & $504 / 28$ & $4 X 700$ \\
\hline 12 & 68 & EBRT+BRT & IIB & SCC & $504 / 28$ & $4 X 700$ \\
\hline 13 & 72 & EBRT+BRT & IIB & SCC & $504 / 28$ & $4 X 700$ \\
\hline 14 & 58 & EBRT+BRT & IIIA & SCC & $504 / 28$ & $4 X 700$ \\
\hline 15 & 60 & EBRT+BRT & IIB & SCC & $504 / 28$ & $4 X 700$ \\
\hline
\end{tabular}

Tüm hastalara Varian DHX lineer hızlandırıcı ile yoğunluk ayarlı radyoterapi (IMRT) kullanılarak 28 fraksiyonda 50.4 Gy tüm pelvik EBRT verildi. EBRT tedavisinden sonra HDR BRT, Ir192 kaynaklı GammaMed Plus BRT cihazı kullanılarak 4 fraksiyonda 28 Gy merkezi hastalığa verildi.
$\mathrm{Bu}$ çalışmada bilgisayarlı tomografi(BT) ve manyetik rezonans (MR) uyumlu tandem ovoid (TO) aplikatörler kullanıldı.

\subsection{Intrakaviter BRT Aplikasyonu}

Tedavi öncesinde damar yolunun açılması, hastanın aç karnına olması ve rektumun boş olması önemlidir. İntrakaviter BRT aplikasyonu yapılmadan önce anestezi altında ayrıntılı bir jinekolojik muayene yapılmalıdır. Muayenede uterusun ve vajinanın boyutları ve pozisyonları değerlendirilmelidir. Kullanılacak aplikatörler mutlaka düzenli olarak sterilize edilmelidir. Mesaneye uygun boyutta idrar sondası yerleştirilir. Tandem ve ardından ovoid dikkatli bir şekilde yerleştirilip sabitlenir daha sonra packing işlemine geçilir. Packing, radyoopak madde içeren gazlı bezlerin vajen içerisine yerleştirilmesidir. Bu işlemin amacı rektum ve mesane gibi kritik organların mukozalarının aplikatörden uzaklaştırılmasıdır. Tendem ovoid aplikatör uygulamasında 15 hastanın her biri için uzunluğu $14 \mathrm{~cm}$ ve $45^{\circ}$ açılı tandem, $3 \mathrm{~cm}$ çapında fletcher tipi ovoidler kullanılmıştır. Uygun ovoid seçimi, doktor ve merkezlere bağlı değişmekte olup mümkün olan en geniş çaplı aplikatörün seçilmesi önemlidir.

\subsection{Simülasyon ve Tedavi Planlaması}

Bütün hastalara, aplikatörler yerleştirildikten sonra BT taramas1 yapıldı. BT simülasyon protokolü olarak 100-120 kVp tüp gerilimi, 300-350 mA akım değeri ve $2 \mathrm{~mm}$ kesit kalınlığı kullanıldı. Simülasyon işlemlerinden sonra BT görüntüleri, tıpta dijital görüntüleme ile iletişim (DICOM) bağlantısı yoluyla Varian Eclips-Brachyvision Versiyon 15.1 (Varian, Palo Alto, CA) brakiterapi tedavi planlama sistemine aktarıldı. Konturlama kısmında, yüksek riskli (HR) ve orta riskli (IR) CTV'ler tanımlandı. OAR'ler için; mesane, rektum, sigmoid, ince bağırsak ve üretra çizildi.

HDR BRT için tedavi planlaması ve doz hesaplaması Varian Eclips-Brachyvision Versiyon 15.1 brakiterapi tedavi planlama sistemi (TPS) kullanılarak yapıldı. Tedavi planlarının inverse optimizasyonu sırasında hacim optimizasyon ve aplikatör geometrileri için kullanıcının bağımsız olmasını sağlamak için benzer optimizasyon parametreleri kullanıldı. Ovoidler için maksimum aktif pozisyon aralığ 1 , kateterin ucundan $4 \mathrm{~cm}$, tandem için ise $6 \mathrm{~cm}$ olarak ayarlandı. Klinik protokolü olarak, CTVHR'in \%90'1 için 2 Gy fraksiyonunda eşdeğer doz (EQD2) (EBRT+BRT) için en az 85 Gy ve CTVIR'in \%90'1 için EQD2'nin en az 65 Gy alması göz önünde bulundurulmuştur. OAR'lerin D2cm3'nün mesanenin 90 Gy ayrıca rectum,sigmoid ve ince bağırsağın 75 Gy' in altında olmasına dikkat edilmiştir. CTV'ler için $\alpha / \beta$ oranı 10 Gy, OAR'ler için $\alpha / \beta 3$ Gy alınmıştır.

Brakiterapide farklı tedavi optimizasyonları bulunmaktadır. Şekil 1.a.'da gösterildiği gibi manuel optimizasyon tekniğinde, istenen doz seviyesini elde etmek için kaynağın süresi ve duruş yeri manuel olarak ayarlanır ve hedefe gidilmeye çalışılır. Manuel optimizasyon için hedeflenen plan parametreleri Tablo II.' de verilmiştir. Şekil 1.b.' de gösterildiği gibi manuel optimizasyonun aksine inverse optimizasyon tekniğinde hedef hacim için almasını istediğimiz dozlar tanımlanır, OAR için ise maksimum 
Gül O.V, ve ark.

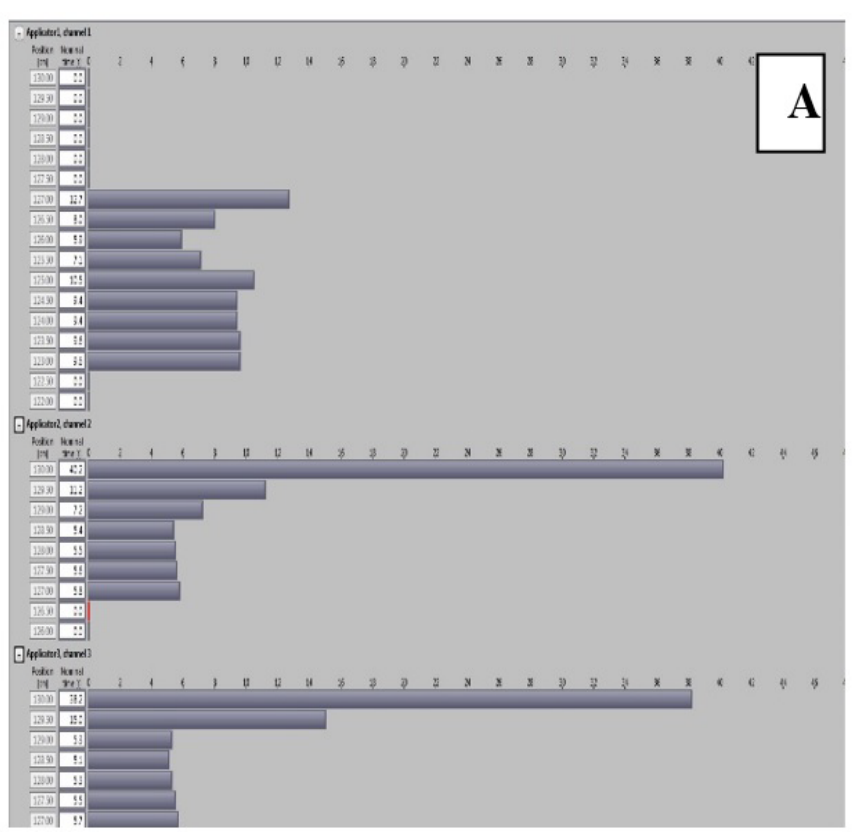

Şekil 1. A:Manuel optimizasyon kaynak duruş ve süreleri

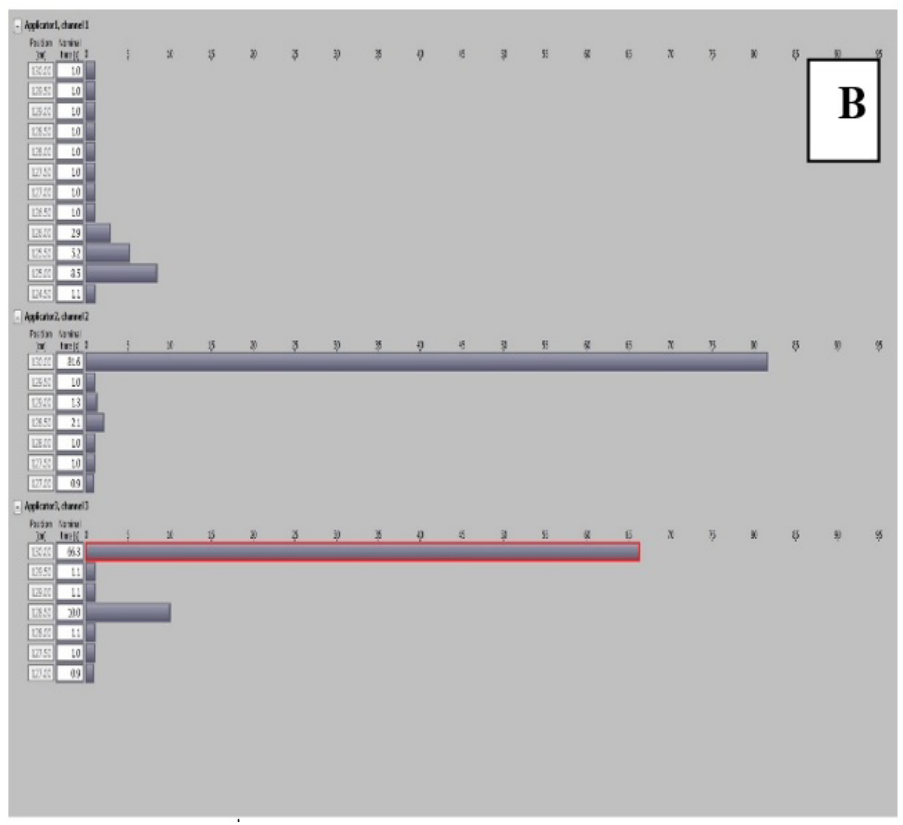

B:İnverse optimizasyon kaynak duruş ve süreleri

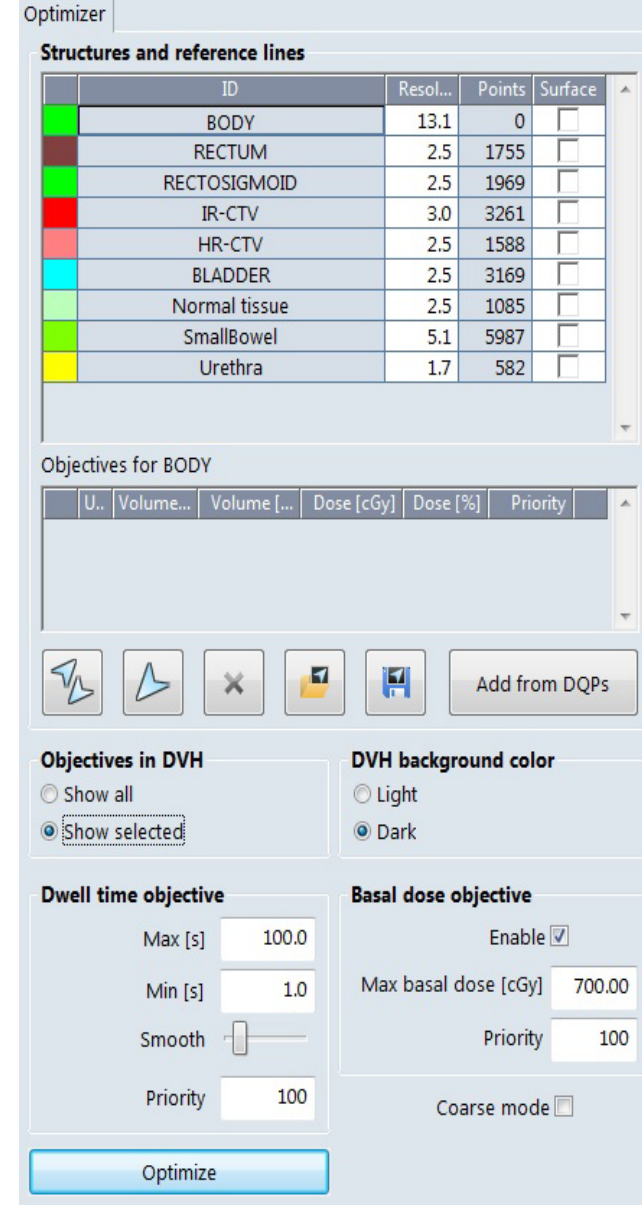

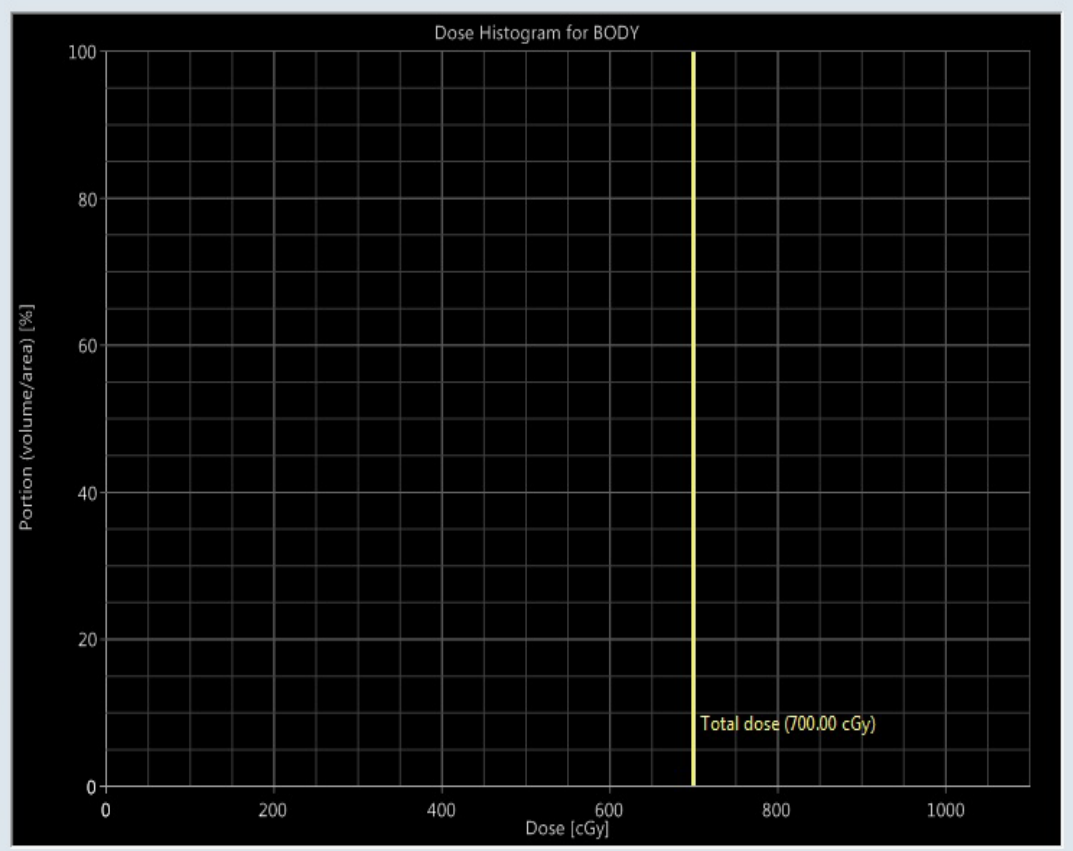

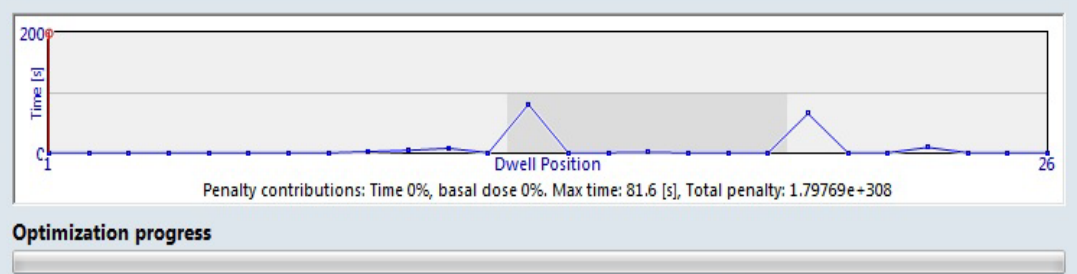

Close \& Calculate Final Dose $\rightarrow$

Şekil 2. İnverse optimizasyon penceresi 
Serviks Kanseri İçin İki Farklı Brakiterapi Tedavi Planlama Tekniğinin Dozimetrik Karşılaştırması

almasını istediğimiz doz ve hacimi tanımlanarak istediğimiz dozların elde edilmesi amaçlanır. Bu istekler doğrultusunda IO’ da kaynak duruş yeri ve süresi otomatik tanımlanır. İnverse optimizasyon kısmı Şekil 2.' de gösterilmiştir ayrıca plan parametreleri Tablo III.' de verilmiştir.

Tablo II. Manuel optimizasyon için hedeflenen plan parametreleri

\begin{tabular}{ll}
\hline Parametreler & Optimizasyon hedefleri \\
\hline CTVHR & $\mathrm{D} 90 \geq 700 \mathrm{cGy} / \mathrm{fr}$ \\
CTVIR & $\mathrm{D} 50 \geq 700 \mathrm{cGy} / \mathrm{fr}$ \\
Rektum & $\mathrm{D} 2 \mathrm{~cm}^{3} \leq 500 \mathrm{cGy} / \mathrm{fr}$ \\
Mesane & $\mathrm{D}_{2 \mathrm{~cm}^{3} \leq 700 \mathrm{cGy} / \mathrm{fr}}$ \\
İnce bağırsak & $\mathrm{D}_{2 \mathrm{~cm}^{3}} \leq 150 \mathrm{cGy} / \mathrm{fr}$ \\
Sigmoid & $\mathrm{D} 2 \mathrm{~cm}^{3} \leq 200 \mathrm{cGy} / \mathrm{fr}$ \\
Üretra & $\mathrm{D} 2 \mathrm{~cm}^{3} \leq 600 \mathrm{cGy} / \mathrm{fr}$ \\
\hline
\end{tabular}

$\mathrm{CTV}_{\mathrm{HR}}$ - yüksek riskli klinik hedef volüm, $\mathrm{CTV}_{\mathrm{IR}}$ - orta riskli klinik hedef volüm

Tablo III. İnverse optimizasyon için plan parametreleri

\begin{tabular}{|c|c|c|}
\hline Parametreler & Optimizasyon hedefleri & Ağırlıklaı \\
\hline \multirow[t]{2}{*}{ CTVHR $_{\text {HR }}$} & $\mathrm{D} 90 \geq 700 \mathrm{cGy} / \mathrm{fr}$ & 100 \\
\hline & $\mathrm{D} 5 \leq 700 \mathrm{cGy} / \mathrm{fr}$ & 50 \\
\hline CTVIR & $\mathrm{D} 50 \geq 700 \mathrm{cGy} / \mathrm{fr}$ & 100 \\
\hline Rektum & $\mathrm{D} 2 \mathrm{~cm}^{3} \leq 500 \mathrm{cGy} / \mathrm{fr}$ & 80 \\
\hline Mesane & $\mathrm{D} 2 \mathrm{~cm}^{3} \leq 600 \mathrm{cGy} / \mathrm{fr}$ & 75 \\
\hline İnce bağırsak & $\mathrm{D} 2 \mathrm{~cm}^{3} \leq 150 \mathrm{cGy} / \mathrm{fr}$ & 60 \\
\hline Sigmoid & $\mathrm{D} 2 \mathrm{~cm}^{3} \leq 200 \mathrm{cGy} / \mathrm{fr}$ & 60 \\
\hline Üretra & $\mathrm{D}_{2} \mathrm{~cm}^{3} \leq 600 \mathrm{cGy} / \mathrm{fr}$ & 60 \\
\hline
\end{tabular}

\subsection{Istatistiksel Analiz}

Tüm veriler Sosyal Bilimler için İstatistiksel Paket (SPSS) yazılımında (sürüm 25.1, IBM) kaydedildi ve analiz edildi. İki farklı tedavi planı için ortalama ile standart sapma hesaplandı ve arasındaki ilişkiyi değerlendirmek için Paired Samples t- testi kullanıldı. $\mathrm{P}<0.05$ istatistiksel olarak anlamlı kabul edildi.

\section{BULGULAR}

Yapılan çalışmada 15 hastada MO ve IO planlamalar hem hedef hem de kritik organlar açısından değerlendirilmiştir ve CTVHR için doz sarısı Şekil 3' de gösterilmiştir.

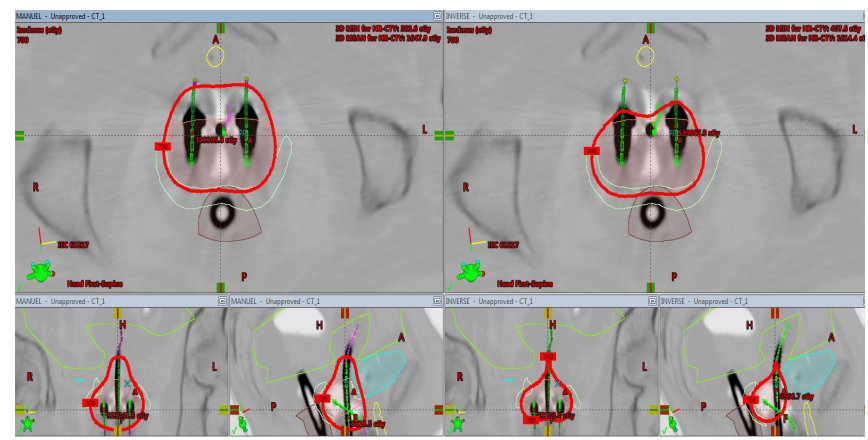

Şekil 3. Manuel ve İnverse optimizasyon için 700cGy doz dağılımı
Önerilerine göre hedef hacim için dose volüm histogram (DVH)' dan CTVHR D90'ın ve CTVIR D50'nin 700 cGy değerine; kritik organlardan D2cm'lik volümler için özellikle mesanenin $700 \mathrm{cGy}$, rectum ve sigmoidin ise 500cGy altında kalması göz önünde bulundurularak optimizasyonlar yapılmıştır. CTV ve OAR' ler için DVH parametreleri Tablo IV. ve Tablo V.' de verilmiştir.

Tablo IV. Klinik hedef hacim için doz istatistik karşılaştırması

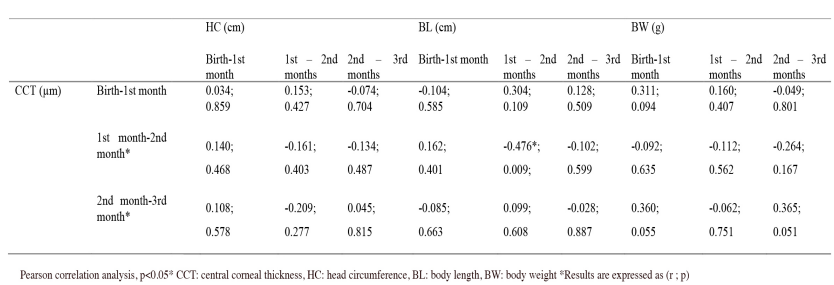

Tablo V. Kritik organlar için doz istatistik karşılaştırması

\begin{tabular}{|c|c|c|c|c|c|}
\hline Parametreler & & $\begin{array}{l}\text { MO } \\
\text { (Ortalama } \pm \text { SS) }\end{array}$ & $\begin{array}{l}\text { I0 } \\
\text { (Ortalama } \pm S S)\end{array}$ & $\begin{array}{l}\Delta \text { Ortalama } \pm \text { SS } \\
\text { (MO-IO) }\end{array}$ & $p$ \\
\hline \multirow[t]{3}{*}{ Rektum } & $\mathrm{D}_{2 \mathrm{~cm} 3}$ (cGy) & $531.08 \pm 39.38$ & $493.86 \pm 45.70$ & $37.22 \pm 53.31$ & 0.043 \\
\hline & D0.1cm3 (cGy) & $701.24 \pm 62.63$ & $677.74 \pm 68.30$ & $23.50 \pm 71.29$ & 0.300 \\
\hline & $V_{5 G y}\left(\mathrm{~cm}^{3}\right)$ & $3.02 \pm 1.15$ & $2.07 \pm 1.00$ & $0.95 \pm 1.48$ & 0.059 \\
\hline \multirow[t]{3}{*}{ Mesane } & $\mathrm{D}_{2 \mathrm{~cm} 3}(\mathrm{cGy})$ & $615.93 \pm 121.76$ & $430.65 \pm 74.06$ & $185.27 \pm 84.67$ & 0.000 \\
\hline & Do.lcm3 (cGy) & $860.98 \pm 189.05$ & $586.15 \pm 112.29$ & $274.83 \pm 129.87$ & 0.000 \\
\hline & $\mathrm{V}_{50 \mathrm{yy}}\left(\mathrm{cm}^{3}\right)$ & $7.09 \pm 4.94$ & $0.91 \pm 0.72$ & $6.17 \pm 4.71$ & 0.001 \\
\hline \multirow[t]{3}{*}{ İnce bağırsak } & $\mathrm{D}_{2 \mathrm{~cm} 3}(\mathrm{cGy})$ & $143.12 \pm 63.77$ & $149.53 \pm 86.07$ & $6.40 \pm 45.34$ & 0.649 \\
\hline & $\mathrm{D}_{0.1 \mathrm{~cm} 3}$ (cGy) & $250.58 \pm 165.87$ & $223.80 \pm 174.77$ & $26.77 \pm 43.08$ & 0.066 \\
\hline & $\mathrm{V}_{5 \mathrm{~Gy}}\left(\mathrm{~cm}^{3}\right)$ & $0.10 \pm 0.13$ & $0.45 \pm 0.56$ & $0.35 \pm 0.49$ & 0.041 \\
\hline \multirow[t]{3}{*}{ Sigmoid } & $\mathrm{D}_{2 \mathrm{~cm} 3}(\mathrm{cGy})$ & $226.11 \pm 78.44$ & $212.29 \pm 74.89$ & $13.82 \pm 40.07$ & 0.279 \\
\hline & $\mathrm{D}_{0.1 \mathrm{~cm} 3}$ (cGy) & $271.51 \pm 109.25$ & $258.95 \pm 121.84$ & $12.56 \pm 33.10$ & 0.237 \\
\hline & $V_{5 G y}\left(\mathrm{~cm}^{3}\right)$ & $0.16 \pm 0.07$ & $0.02 \pm 0.03$ & $0.14 \pm 0.08$ & 0.000 \\
\hline \multirow[t]{3}{*}{ Üretra } & $\mathrm{D}_{2 \mathrm{cms}}(\mathrm{cGy})$ & $659.66 \pm 176.01$ & $415.28 \pm 189.24$ & $244.38 \pm 132.51$ & 0.000 \\
\hline & $\mathrm{D}_{1 \mathrm{~cm} 3}$ (cGy) & $687.95 \pm 184.06$ & $458.60 \pm 168.21$ & $229.34 \pm 122.48$ & 0.000 \\
\hline & D0.1cms (cGy) & $724.07 \pm 195.80$ & $505.85 \pm 161.53$ & $218.22 \pm 133.18$ & 0.000 \\
\hline
\end{tabular}

Hedef hacim olan CTVHRD90 ve CTVIR D50 için iki tedavi plan optimizasyonu için benzer sonuçlar bulunmuştur ancak CTVHRD98 ile CTVIR D90 ve CTVIR D98 için IO'un üstünlüğü görülmektedir ( $\mathrm{p}=0.000)$. Kritik organlar açısından rektumun D2cm3 için $(\mathrm{p}<0.043)$, mesanenin D2cm3, D0.1 cm3 ve V5Gy için $(\mathrm{p}<0.000)$, ince bağırsağın V5Gy için $(\mathrm{p}<0.041)$, sigmoidin V5Gy için $(\mathrm{p}<0.041)$, üratranın D2cm3 , D0.1 cm3 ve V5Gy için $(\mathrm{p}<0.000)$ anlamlı fark bulunmuş ve IO' un MO göre kritik organları daha iyi koruduğu görülmüştür (Şekil 4).

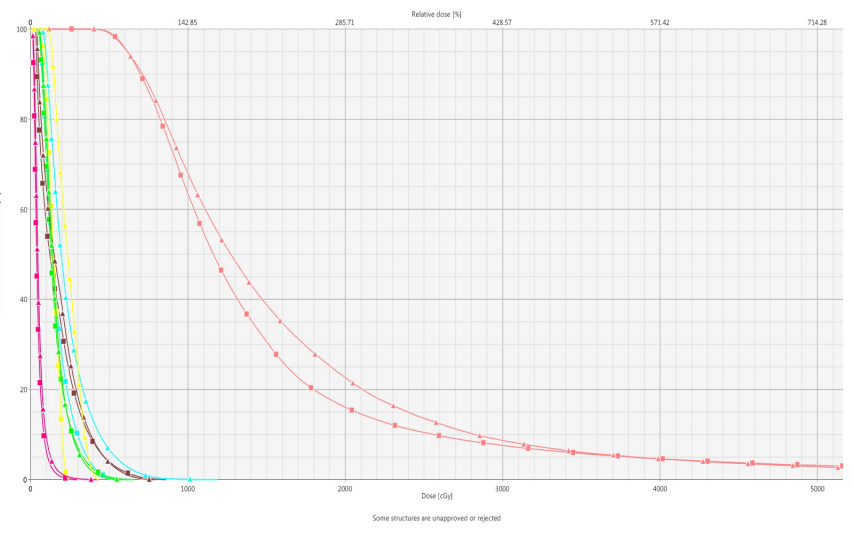

Şekil 4. Manuel ve İnverse optimizasyon için doz volüm histogram karşılaştırması; Turuncu CTVHR, kahverengi: rektum, mavi: mesane, yeşil: sigmoid, sarı: üretra, pembe: bağırsak

$\boldsymbol{\Delta}$ : Manuel optimizasyon $\mathbf{m}$ : İnverse optimizasyon 
Gül O.V, ve ark.

Şekil 5'den görüleceği gibi inverse optimizasyon ile yapılan tedavi planlarının işınlama süreleri manuel optimizasyona göre daha kısadır. Ayrıca inverse optimizasyonda hedef ve kritik organlar için girilen optimizasyon parametreleri kaydedilmesi ve sonraki benzer hastalarda kullanım kolaylığ sağlaması açısından planlama süresinde de kısalma sağlayacaktır.

\section{TARTIŞMA}

Brakiterapi serviks kanseri tedavisinin çok önemli bir parçasıdır. Bu çalışmanın amacı, serviks kanseri hastalarında manuel ve inverse optimizasyon yöntemleri ile elde edilen HDR tandem-ovoid brakiterapi planlarında ki DVH parametrelerinin karşılaştırılmasıdır. GEC-ESTRO jinekolojik çalışma grubu, hedef hacimlerin çizilmesinde ortaya çıkan farkları ortadan kaldırmak için, CTVHR ve CTVIR tanımlanmasını önermektedir. Özellikle inverse optimizasyon yönteminde hedef ve riskli organların doğru olarak tanımlanması daha da önem kazanmaktadır. Çalışmamızda MO ve IO teknikleri ile yapılan planlarda sırasıyla CI değerleri 1.54 ve 1.27 olarak bulunmuştur. Serviks intrakaviter brakiterapisinde IO, MO kıyasla hedef hacim kapsamı ve uygunluk endeksinde özellikle yüksek oranda doz sarışı ile önemli bir iyileşme göstermiştir. Palmqvist ve ark. (17) serviks kanseri brakiterapisi için yaptıkları MO ve IO planlama yaklaşımları arasındaki dozimetrik karşılaştırmasında, iki tekniğin kritik organların korumasında yakın sonuçlar verdiğini ancak hedef volüm kapsamasında IO tekniğinin üstünlüğünü göstermişlerdir. Bizim yapmış olduğumuz çalışma Palmqvist ve ark. araştırması ile uyumludur. Ayrıca IO tekniğinin kritik organları daha iyi koruduğu görülmüştür. Ram Abhinav Kannan ve ark. (18) bizim çalışmamızda olduğu gibi IO hedef hacim kapsamı açısından MO ile karşılaştırıldığında, IO tekniğinin daha üstün olduğunu bulmuşlardır.

Trnkova ve ark. (19) tarafindan manuel ve inverse optimizasyon yöntemleri ile elde edilen planlamaların karşılaştırıldığ aldığ 1 doz değerlerinde inverse optimizasyonda anlamlı bir değişiklik görülmezken, rektumun D2cc hacminin aldığ $\mathrm{doz}$ değerleri anlamlı olarak daha düşük saptanmıştır. Bizim çalışmamızda da MO için mesanenin D2cm3 615.93 cGy çıkmış iken, IO için mesane D2cm3 430.65 cGy ayrıca rektum için D2cm3 531.08 cGy çıkmış iken, IO'da rektum D2cm3 493.96 cGy çıkmıştır. Swamidas ve ark. (20) tandem ovoid'in kullanıldığı intrakaviter brakiterapi için manuel ve inverse optimizasyonun karşılaştırıldığı dozimetrik çalışmada, CTVHR D90 için anlamlı bir fark bulunmamış iken, kritik organlardan mesane için anlamlı fark bulunmuş ve MO için mesane D2cm3 710 cGy, IO için mesanenin D2cm3 650 cGy bulunmuştur. Bizim çalışmamızda ise MO için mesanenin D2cm3 615.93 cGy, IO için mesanenin D2cm3 430.65 cGy bulunmuştur. Ayrıca bu üstünlük sadece mesane için değil diğer kritik organlardan rektum ve üretra için de geçerlidir. İntrakaviter serviks brakiterapisinde, hasta içerisinde aplikatörler sabitlendiği için zaman çok önemlidir. IO tedavi planlama süresi ve Şekil 5.' de gösterildiği gibi aktif ışınlama süresi MO tekniğine göre daha kısa sürmektedir.

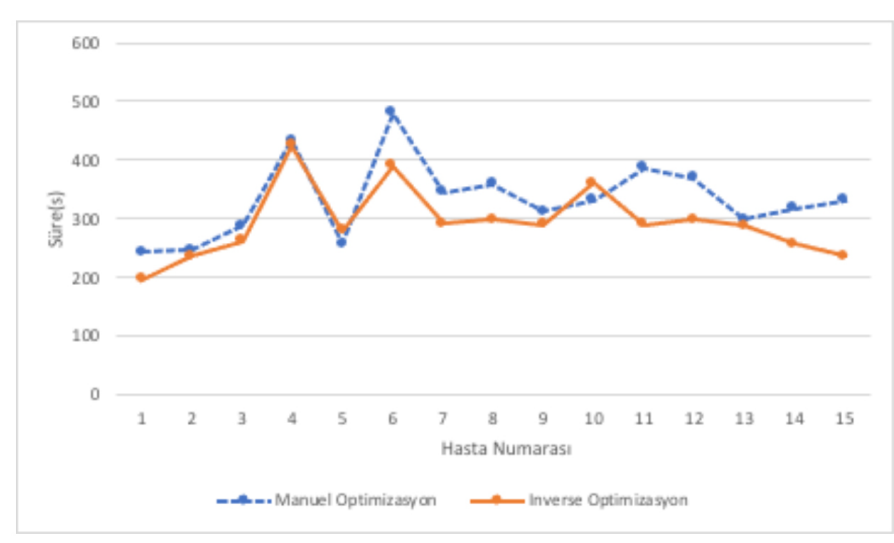

Şekil 5. Manuel optimizasyon ile inverse optimizasyon ışınlama süresi karşılaştırması

\section{SONUÇ}

Sonuç olarak, bu çalışmada IO yöntemi kullanılarak yapılan planlarda MO planlarına göre, aplikasyon içindeki homojen doz dağılımı daha iyi olmakla birlikte, istenen doz dağılımıyla tümör hacminin daha iyi kapsanması, mesane, rektum ve sigmoid gibi kritik organların daha az doz alması sağlanmiştir.

Etik Komite Onayı: Selçuk Üniversitesi Tıp Fakültesi Yerel Etik Kurulu'ndan 30.09.2020 tarih 2020/424 sayılı izin alındı ve makalede Araştırma ve Yayın Etiğine uyuldu.

Yazar Katkıları: Fikir - O.G.; Tasarım - O.G.; Denetleme O.G.; Kaynaklar - H.B.; Malzemeler - H.B.; Veri Toplanmas1 ve/veya İşlemesi - G.İ.; Analiz ve/veya Yorum - O.G.; Literatür Taraması - H.B.; Yazıyı Yazan - O.G.; Eleştirel İnceleme - G.I.;

Çıkar Çatışması: Yazarların beyan edecek çıkar çatışması yoktur.

Finansal Destek: Yazarlar bu çalışma için finansal destek almadıklarını beyan etmişlerdir. 
KAYNAKLAR

1. Khan F.M: The Physics of Radiation Therapy 3rd Edition. Lippincott Williams \& Wilkins Company, USA, 2010 .

2. Lee D.H, Cho J.K, Shin K.H, Shin D, Yoon M, Park S.Y, Lee S.B, Kim J.Y, Cho K.H, Lee J.W, Chung J.B, Choe B.Y, Choi K.S, Suh T.K. Intravaginal Packing Efects of CT-Guided Intracavitary Radiotherapy for Cervical Cancer. Korean Physical Society 2009; 54: 250-254.

3. Baltas, Sakelliou D, Zamboglou L. The Physics of Modern Brachytherapy for Oncology 2007.

4. Holloway C, Racine M.L, Cornack R.A, O'Farrell D.A, Viswanathan A.N. Sigmoid Dose Using 3D Imaging in Cervical-CancerBrachytherapy. Radiotherapyand Oncology 2009; 93(2): 307-310.

5. Haie-Meder C, Pötter R, Limbergen E.V, Briot E, DeBrabandere M, Dimopoulos J, Dumas I, Hellebust T.P, Kirisits C, Lang S, Muschitz S, Nevinson J, Nulens A, Petrow P, Serstner N.W. Recommendations from Gy naecological (GYN) GEC-ESTRO Working Group(I): concept sand terms in 3D image based 3D treatment planning in cervix cancer brachytherapy with emphasis on MRI assessment of GTV and CTV. Radiotherapy and Oncology $2005 ; 74: 235-245$.

6. International Commission on Radiation Unit sand Measurements. Gynaecological brachytherapy, 1985.

7. Limbergen E.V, Pötter R, Hoskin P, Baltas D: GEC ESTRO (European Society for Radiotherapy and Oncology) Handbook of Brachytherapy. ESTRO, 2014.

8. Muller R, Runkel R. Measurement of dosimetric parameters for the Alphaomega high-dose-rate iridium-192 source. Medical Dosimetry 2005; 30(3):139-142.

9. Podgorsak E.B: Radiation Oncology Physics: A Handbook for Teachersand Students. IAEA, 2005.

10. Khan, F.M: The Physics of Radiation Therapy. Third Edition. Baltimore: Lippincott, Williams and Wilkins, 2003.

11. Glenn P. Glasgow, Chairman J. Daniel Bourland Perry W. Grigsby Jerome A. Meli Keith A. Weaver : Remote Afterloading Technology. Published for the American Association of Physicists in Medicine by the American Institute of Physics, 1993.

12. Plato Brachytherapy Remote Afterloading User Manuel.14.0 version. The Nethelands. Nucletron.
13. Perez C.A., Grigsby P.W., Castro-Vita H., Lockett M.A. "Carcinoma of theuterinecervix. I. impact of prolongation of overall treatment time and timing of brachytherapy on outcome of radiationtherapy". Int J Radiation Oncology Biology Physics 1995;32(5):1275-1288.

14. Anbumani S, Anchineyan P, Narayanasamy A, Palled SR, Sathisan S, Jayaraman P, et al. Treatment planning methods in high dose rate interstitial brachytherapy of carcinoma cervix: a dosimetric and radiobiological analysis. ISRN Oncol 2014; 2014:125020.

15. Gelover E, Katherine C, Mart C, Sun W, Kim Y. Patient's specific integration of OAR doses (D2 cc) from EBRT and 3D image-guided brachytherapy for cervical cancer. J Appl Clin Med Phys 2018; 19(2):83-92.

16. Kannan RA, Gururajachar JM, Ponni A, Koushik K, Kumar M, Alva RC, et al. Comparison of manual and inverse optimisation techniques in high dose rate intracavitary brachytherapy of cervical cancer: A dosimetric study. Rep Pract Oncol Radiother 2015; 20(5):365-9.

17. Palmqvist $\mathrm{T}$, Dybdahl Wanderas A, Langeland Marthinsen AB, Sundset M, Langdal I, Danielsen S, et al. Dosimetric evaluation of manually and inversely optimized treatment planning for high dose rate brachytherapy of cervical cancer. Acta Oncol 2014; 53(8):1012-8.

18. Kannan R.A., Gururajachar J.M., Ponni A., Koushik K., Kumar M., Alva R.C., Harjani R., Murthy A. Comparison of manual and inverse optimisation techniques in high dose rate intracavitary brachytherapy of cervical cancer: A dosimetric study. Reports of Practical Oncology \& Radiotherapy 2015;20(5):365-369.

19. Trnkova P, Pötter R, Baltas D, Karabis A. New inverse planning technology for imageguided cervical cancer brachytherapy: Description and evaluation with in a clinical frame. Radiotherapy and Oncology 2009; 93:331-340.

20. Swamidas V. Jamema, Christian Kirisits, Umesh Mahantshetty. et al. Comparison of DVH parameters and loading patterns of standard loading, manual and inverse optimization for intracavitary brachytherapy on a subset of tandem/ovoid cases Radiother Oncol. 2010;97(3):501-506. 